\title{
Comparative Accuracy Analysis of GNSS Observation for Positioning with A Combination of GPS, GLONASS, and BEIDOU Satellite
}

\author{
Wahyu Ristanto, Khomsin, and Ira Mutiara Anjasmara
}

\begin{abstract}
GNSS (Global Navigation Satellite System) is a term used for the entire global navigation satellite system that already operate or are in the planning. some of them namely GPS, GLONASS, and BeiDou. Errors due to less powerful satellite geometry when data retrieval, in teoritik can be resolved with receiver technological advances that was able to capture many of satellite signals. Hi Target V30 is one of GNSS receivers are able to catch GPS, GLONASS and BeiDou signal, with more satellite signals that can be received are expected to improve the accuracy of positioning. From this study is known that the use of BEIDOU satellite not too influential on the GPS satellites, but will add to the accuracy of the GLONASS satellite. This is demonstrated by the existence of a reduction in average value on difference coordinates and RMS error reduce from $1,068 \mathrm{~m}$ into $0371 \mathrm{~m}$. The use of GPS + GLONASS + BEIDOU and GPS + GLONASS satellite combinaton provide the best accuracy with the RMS value of the error remain in the millimeter, while the use of GLONASS satellites alone give the worst accuracy among the strategies with the value of RMS error visible to reach $0585 \mathrm{~m}$ on baseline $\mathrm{C} 2$.
\end{abstract}

Keywords-GNSS, satellite, positioning, Accuracy.

\section{I.INTRODUCTION}

GNSS (Global Navigation Satellite System) is a term used for the entire global navigation satellite system that already operate or are in the planning [1], Some of which are GPS, GLONASS, Galileo, BeiDou, IRNSS, dan QZSS satellite system [2]. The use of GNSS make the extra-terrestrial survey easier and give better precision. The GNSS segment is built by 3 segment, the space segment consisting of GNSS satellite, the control segment comprising a control station network, and the user segment consisting of equipment receiving satellite signal [3]. Basically, GPS can be used at any time regardless of time and weather, GPS can by used both day and night, in bad weather such as rainy or fog [4]. Because of this characteristic, the use of GPS can improve the efficiency and flexibility of positioning. The basic concept of positioning with GPS is resection with distance, by simultaneous measurement of distance to several GPS satellites whose coordinates are known [5]. There are various errors in GPS measurements such as multipath and cycle slip that can affect accuracy [6]. The accuracy of positioning from a GPS survey will generally depend on 4 (four) factors,

Wahyu Ristanto, Khomsin, and Ira Mutiara Anjasmara are with Department of Geomatics Engineering, Institut Teknologi Sepuluh Nopember, Surabaya, 60111, Indonesia. E-mail: ristanto69.wr@gmail.com namely: the accuracy of the data used, the observation geometry, the observation strategy used, and the data processing strategy. The accuracy of the data used will basically depend on three factors, namely: data type (pseudo range or phase), the quality of the receiver, and the level of error and bias affecting the observation data. The observation geometry includes the observer geometry (net) and satellite geometry that depends on the number of satellites, locations, and distribution of satellites received. Theoretically, the more satellites received, the better satellite geometry [7]. The evolving receiver technology can overcome the error of less satellite geometry when retrieving data [ 8 ] . Hi-Target V30 is one of the GNSS receivers capable of capturing GPS, GLONASS and BeiDou satellites signals, with a growing number of satellite signals we get, we expect to improve the accuracy of positioning. Based on the specifications of Hi Target receivers, the accuracy of static surveys is $2.5 \mathrm{~mm}$ for horizontal accuracy and $5 \mathrm{~mm}$ for vertical [9]. In this research we will analyze the use of three combinations of GPS, GLONASS and BeiDou satellites using Hi Target V30 receiver. GPS is a satellite developed by the United States. GLONASS was developed by the Soviet Union (Russia) [10], and BeiDou is a navigation satellite developed by China. With the use of more satellites it will get more data which expected to increase the accuracy of GNSS surveys.

\section{DATA SETS AND METHODOLOGY}

The test site research is Surabaya, East Java Indonesia with 8 point observation in used. The observation geometry network design can be seen in Figure 1.

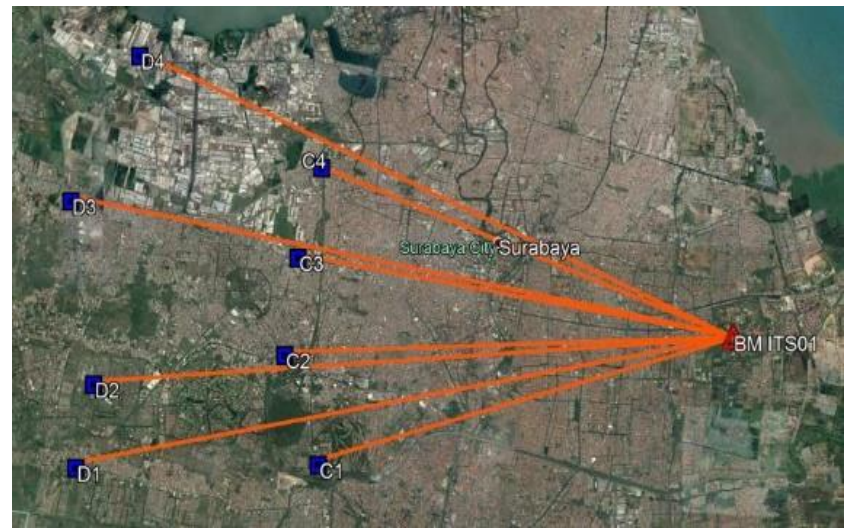

Figure 1. Observation Geometry Network Design. 
The design consists of 8 baselines with baseline lengths of $10 \mathrm{KM}$ and $15 \mathrm{KM}$ for each 4 baselines. The base point is at BM ITS 01 in front the rectorate building of Institut Teknologi Sepuluh Nopember Surabaya.

Data obtained by GNSS observation on 14 and 15 April 2018 using Hi-Target V30 receiver. GNSS observation were performed in 1 hour with 5 second interval and $15^{\circ}$ mask angle. Data from observation will be converted to rinex file using HGO (Hi Target Geomatics Office) software and the data processing which is done using Topcon Tools, the rinex data will be process using 6 strategies, namely:

1. Strategy 1: the data processing using GPS + GLONASS + BeiDou satellite signal combinations,

2. Strategy 2: the data processing using GPS + GLONASS satellite signal combinations,

3. Strategy 3: the data processing using GPS + BeiDou satellite signal combinations,

4. Strategy 4: the data processing using GLONASS + BeiDou satellite signal combinations,

5. Strategy 5: the data processing using GPS satellite signal combinations,

6. Strategy 6: the data processing using GLONASS satellite signal combinations.

The processing will be done separately every strategy. This process includes measurement data inputs such as receiver height and point definition, then the selection of data to be used, followed by post- processing and reporting in the last.

\section{RESULT AND DISCUSSIONS}

After data processing steps are passed from baseline processing, it will yield data processing result contains UTM coordinates in zone 49S and RMS (root mean square) error for each point measurement

\section{A. Analysis of Differences of Coordinates of Data Processing Results}

The coordinates result from each processing will be reduced against strategy 1 and the result will be converted to an absolute value to avoid a negative value.

1) Analysis of Strategy 1 and 2 Coordinate Result. On strategy 1 and strategy 2 we got the same result, there is no difference in both for all point. From this result we can assume that the addition of BeiDou signal not to influence the processing of GPS + GLONASS satellite signal combination.

2) Analysis of Strategy 1 and 3 Coordinate Result.

TABLE 1.

COORDinATE DifFERENCE STRATEgY 1 AND 3

\begin{tabular}{|c|c|c|c|}
\hline Point & Northing (m) & Easting (m) & Elevation (m) \\
\hline $\mathrm{C} 1$ & 0.017 & 0.019 & 0.001 \\
\hline $\mathrm{C} 2$ & 0.001 & 0.007 & 0.022 \\
\hline C3 & 0.002 & 0.005 & 0.016 \\
\hline C4 & 0.003 & 0.017 & 0.013 \\
\hline D1 & 0.029 & 0.034 & 0.059 \\
\hline D2 & 0.002 & 0.001 & 0.029 \\
\hline D3 & 0.003 & 0.007 & 0.004 \\
\hline D4 & 0.005 & 0.026 & 0.031 \\
\hline
\end{tabular}

Based on Table 1 and Figure 2 shows that the addition of GLONASS satellites gives effect to the result of the coordinates obtained. Coordinate results change in all aspects, both $\mathrm{N}, \mathrm{E}$, and $\mathrm{Z}$. The biggest difference is at point D1 where the biggest change occurs with the value of $0.029 \mathrm{~m}$ for northing, $0.034 \mathrm{~m}$ for easting and $0.059 \mathrm{~m}$ for elevation.

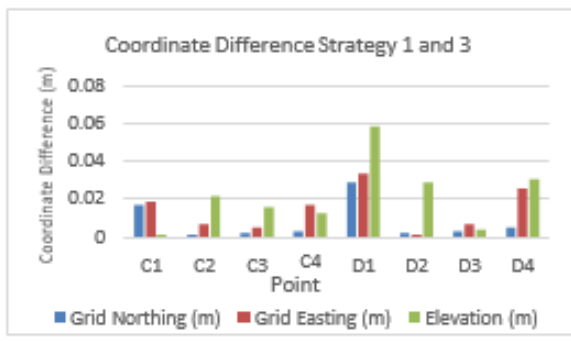

Figure 2. Coordinate Difference Strategy 1 and 3.

3) Analysis of Strategy 1 and 4 Coordinate Result.

TABLE 2.

COORDINATE DIFFERENCE STRATEGY 1 AND 4

\begin{tabular}{cccc}
\hline \hline Point & Northing $(\mathbf{m})$ & Easting $(\mathbf{m})$ & Elevation $(\mathbf{m})$ \\
\hline C1 & 0.174 & 1.068 & 1.399 \\
C2 & 0.063 & 0.034 & 0.075 \\
C3 & 0 & 0.001 & 0.002 \\
C4 & 0.054 & 0.009 & 0.18 \\
D1 & 0.036 & 0.04 & 0.075 \\
D2 & 0.004 & 0.019 & 0.006 \\
D3 & 0.001 & 0.002 & 0.047 \\
D4 & 0.414 & 0.355 & 0.386 \\
\hline \hline
\end{tabular}

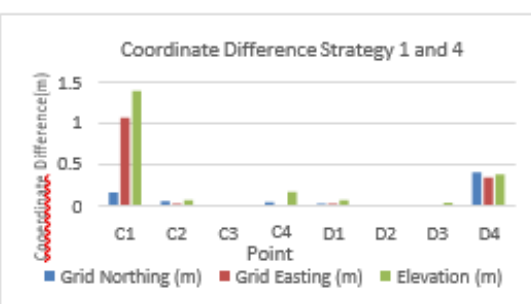

Figure 3. Coordinate Difference Strategy 1 and 4.

From on Table 2 and Figure 3 the results are not good at one point, i.e. at point $\mathrm{C} 1$, the coordinate difference reaches more than $1 \mathrm{~m}$ for the value of $\mathrm{E}$ and $\mathrm{Z}$. Big difference is also present at point $\mathrm{D} 4$ above $0.3 \mathrm{~m}$ in all the coordinates. As for the other point is below $0.08 \mathrm{~m}$. but here there is a point that does not change at any northing coordinate that is at point $\mathrm{C} 3$ the difference of $\mathrm{N}$ value is $0 \mathrm{~m}$. this indicates that the use of GPS satellites has considerable influence.

4) Analysis of Strategy 1 and 5 Coordinate Result.

In this comparison shows that by using GPS satellites get the same results as the use of GPS + BeiDou satellites. It can be assuming that BeiDou signal does not affect the GPS signal. While for the coordinate results change in all aspects, both $\mathrm{N}, \mathrm{E}$, and Z. The largest difference is at point D1 where the biggest change occurs with the value of $0.029 \mathrm{~m}$ for the northing, $0.034 \mathrm{~m}$ for easting and $0.059 \mathrm{~m}$ for elevation when compared with the results GPS + GLONASS + BeiDou satellite coordinates. This result can be seen in Table 3 and Figure 4. 
IPTEK Journal of Proceedings Series No. (2) (2019), ISSN (2354-6026)

The $3^{\text {rd }}$ Geomatics International Conference 2018

July $12^{\text {th }} 2018$, Institut Teknologi Sepuluh Nopember, Surabaya, Indonesia

TABLE 3.

COORDINATE DIFFERENCE STRATEGY 1 AND 5.

\begin{tabular}{cccc}
\hline \hline Point & Northing $(\mathbf{m})$ & Easting $(\mathbf{m})$ & Elevatin(m) \\
\hline C1 & 0.017 & 0.019 & 0.001 \\
C2 & 0.001 & 0.007 & 0.022 \\
C3 & 0.002 & 0.005 & 0.016 \\
C4 & 0.003 & 0.017 & 0.013 \\
D1 & 0.029 & 0.034 & 0.059 \\
D2 & 0.002 & 0.001 & 0.029 \\
D3 & 0.003 & 0.007 & 0.004 \\
D4 & 0.005 & 0.026 & 0.031 \\
\hline \hline
\end{tabular}

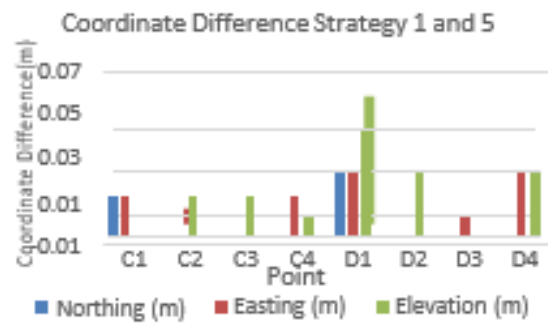

Figure 4. Coordinate Difference Strategy 1 and 5.

5) Analysis of Strategy 1 and 6 Coordinate Result.

The last coordinate difference is in the coordinates of the reduced GLONASS satellite to GPS + GLONASS + BeiDou satellite results. The results of the coordinate differences can be seen in Table 4 and Figure 5.

TABLE 4.

COORDINATE DifFERENCE STRATEGY 1 AND 6

\begin{tabular}{cccc}
\hline \hline Point & Northing $(\mathbf{m})$ & Easting $(\mathbf{m})$ & Elevation $(\mathbf{m})$ \\
\hline C1 & 0.296 & 0.371 & 0.598 \\
C2 & 0.705 & 0.091 & 0.429 \\
C3 & 0 & 0.001 & 0.002 \\
C4 & 0.057 & 0.009 & 0.186 \\
D1 & 0.036 & 0.04 & 0.075 \\
D2 & 0.004 & 0.019 & 0.006 \\
D3 & 0 & 0.003 & 0.044 \\
D4 & 0.414 & 0.359 & 0.387 \\
\hline \hline
\end{tabular}

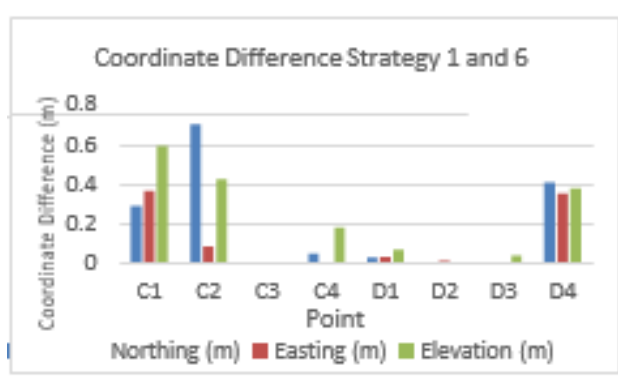

Figure 5. Coordinate Difference Strategy 1 and 6.

Unlike the use of GPS satellites only, based on Table 4 and Figure 5 shows that adding the use of BeiDou satellites affects the GLONASS satellite results. This can be seen from the different values of strategy 4 . In strategy 4 that there is a value above $1 \mathrm{~m}$ at point $\mathrm{C} 1$ decreases to $0.371 \mathrm{~m}$ for the value of E. and here there are 2 unchanged coordinate values, namely northing point $\mathrm{C} 3$ and $\mathrm{D} 3$. So, it can be assuming that the use of the BeiDou satellite improves the accuracy of the position of the GLONASS satellite.

\section{B. RMS Error Analysis}

The value of this RMS error indicates the accuracy of the measurement is smaller or close to zero values obtained, the better the accuracy obtained.

1) $10 \mathrm{KM}$ Baseline RMS Error.

The RMS error rate underwent a substantial change in strategy 4 and strategy 6 . In the RMS horizontal error strategy 4 with the addition of the BeiDou satellite resulted in a smaller value when compared to strategy 6 . The result can be seen in Table 5 and Figure 6.

TABLE 5.

RMS ERROR BASELINE $10 \mathrm{KM}$

\begin{tabular}{ccccccc}
\hline \hline Point & $\mathbf{1}$ & $\mathbf{2}$ & $\mathbf{3}$ & $\mathbf{4}$ & $\mathbf{5}$ & $\mathbf{6}$ \\
\hline C4 & 0.007 & 0.007 & 0.006 & 0.018 & 0.006 & 0.018 \\
C3 & 0.019 & 0.019 & 0.033 & 0.016 & 0.033 & 0.016 \\
C2 & 0.014 & 0.014 & 0.015 & 0.088 & 0.015 & 0.585 \\
C1 & 0.011 & 0.011 & 0.01 & 0.445 & 0.01 & 0.363 \\
\hline \hline
\end{tabular}

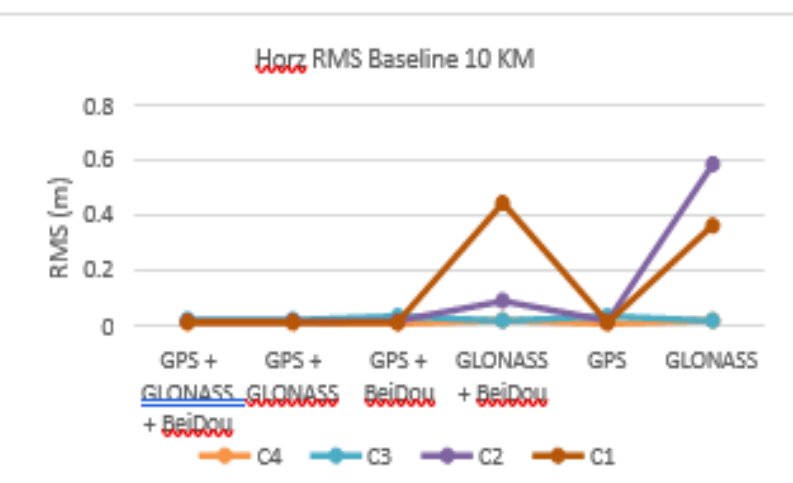

Figure 6. Horizontal RMS Error Baseline $10 \mathrm{KM}$.

2) $15 \mathrm{KM}$ Baseline RMS Error.

TABLE 6.

RMS ERROR BASELINE $15 \mathrm{KM}$

\begin{tabular}{ccccccc}
\hline \hline Point & $\mathbf{1}$ & $\mathbf{2}$ & $\mathbf{3}$ & $\mathbf{4}$ & $\mathbf{5}$ & $\mathbf{6}$ \\
\hline D4 & 0.008 & 0.008 & 0.009 & 0.051 & 0.009 & 0.056 \\
D3 & 0.008 & 0.008 & 0.009 & 0.013 & 0.009 & 0.013 \\
D2 & 0.007 & 0.007 & 0.008 & 0.017 & 0.008 & 0.018 \\
D1 & 0.008 & 0.008 & 0.008 & 0.013 & 0.008 & 0.013 \\
\hline \hline
\end{tabular}

\section{Horz RMS Baseline $15 \mathrm{KM}$}

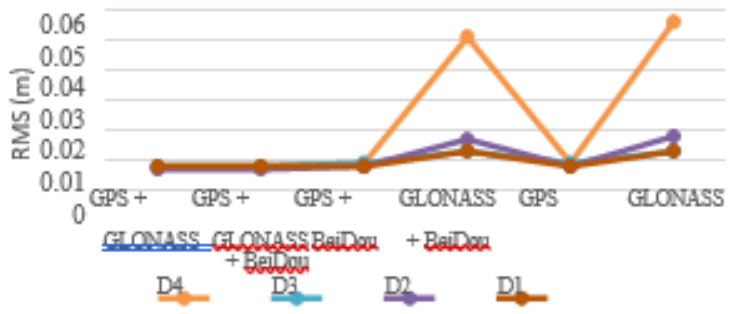

Figure 7. Horizontal RMS Error Baseline $15 \mathrm{KM}$.

The results of the $15 \mathrm{KM}$ baseline RMS error show the same trend as the $10 \mathrm{KM}$ baseline, where the greatest RMS value occurs in the processing using strategy 4 and strategy 6 . 
The $3^{\text {rd }}$ Geomatics International Conference 2018

July $12^{\text {th }} 2018$, Institut Teknologi Sepuluh Nopember, Surabaya, Indonesia

\section{CONCLUSIONS}

The use of different satellites combinations when processing GNSS data affects the accuracy. Different results were obtained based on the processing strategy used.

Processing using strategy 1 and strategy 2 produce the same value. The value generated by using the processing strategy 1 and the processing strategy 2 get the best results among the 6 strategies used. This is seen from the average RMS error in the processing strategy 1 and 2 has the smallest value when compared with other strategies. While the unfavourable results are obtained by using processing strategies 4 and 6 . This is accomplished by the difference of coordinates and the RMS error resulting from both strategies has the biggest value.

The use of BeiDou satellites has little effect on GPS satellites, but the use of BeiDou satellites increases the accuracy of the GLONASS satellites. This is indicated by the presence of value scores on the difference of coordinates and RMS error generated.

\section{REFERENCES}

[1] W. Lechner and S. Baumann, "Global navigation satellite systems," Comput. Electron. Agric., vol. 25, no. 1-2, pp. 67-85, Jan. 2000.

[2] J. Bakara, "Perkembangan Sistem Satelit Navigasi GLobal dan Aplikasinya," Ber. Dirgant., vol. 12, no. 2, pp. 38-47, 2011.

[3] H. Z. Abidin, Penentuan Posisi Dengan GPS Dan Aplikasinya. Jakarta: Pradnya Paramita, 2007.

[4] A. A. Rahmad, M. N. Cahyadi, and S. Sulistiyani, "Analisa Pengolahan Data Stasiun GPS CORS Gunung Merapi Menggunakan Perangkat Lunak Ilmiah GAMIT/GLOBK 10.6," J. Tek. ITS, vol. 5, no. 2, pp. A432-A438, Oct. 2016.

[5] A. El-Rabbany, Introduction to GPS: the Global Positioning System. Artech House, 2002.

[6] Yan Izman and Bambang Rudianto, "Analisis Komparatif Ketelitian Posisi Titik Hasil Pengukuran Dari Satelit Gps Dan Satelit GLONASS," 2011.

[7] Irwan Gumilar, Ananto Indria Pamungkas, Brian Bramanto, and Hasanuddin Z. Abidin, "Contribution of BeiDou Positioning System for Accuracy Improvement: A Perspective," J. Aeronaut. Astronaut. Aviat. Ser. A, vol. 49, no. 3, pp. 171-184, 2017.

[8] Hi Target, "Hi Target Products V30 GNSS RTK System," 2015. . [9] GLONASS, "GLONASS history," 2018.

[10] IAC, "Information and Anaysis center for Positioning, Naviagtion and Timing. Beidou Navigation Satelite System," 2017. 